\title{
GENETIC ENGINEERING STRATEGIES TO PREVENT THE EFFECTS OF ANTIBODY AND COMPLEMENT ON XENOGENEIC CHONDROCYTES
}

\author{
R. Sommaggio ${ }^{1}$, D. Bello-Gil1 ${ }^{1 \S}$, M. Pérez-Cruz ${ }^{1 \S}$, J. L. Brokaw ${ }^{2,3}$, R. Máñez ${ }^{1}$ and C. Costa ${ }^{1,2 *}$ \\ ${ }^{1}$ Infectious Diseases and Transplantation Division, Bellvitge Biomedical Research Institute (IDIBELL) and Bellvitge \\ University Hospital-ICS, Barcelona, SPAIN \\ ${ }^{2}$ Department of Molecular Sciences, Alexion Pharmaceuticals Inc., Cheshire, CT, USA \\ ${ }^{3}$ Global Pharmacovigilance \& Epidemiology, Bristol-Myers Squibb, Wallingford, CT, USA
}

${ }^{\S}$ These authors contributed equally

\begin{abstract}
Advances in animal transgenesis may allow using xenogeneic chondrocytes in tissue-engineering applications for clinical cartilage repair. Porcine cartilage is rejected by humoral and cellular mechanisms that could be overcome by identifying key molecules triggering rejection and developing effective genetic-engineering strategies. Accordingly, high expression of $\alpha 1,2$-fucosyltransferase (HT) in xenogeneic cartilage protects from galactose $\alpha 1,3$-galactose (Gal)-mediated antibody responses. Now, we studied whether expression of a complement inhibitor provides further protection. First, porcine articular chondrocytes (PAC) were isolated from nontransgenic, single and double transgenic pigs expressing HT and moderate levels of human CD59 (hCD59) and their response to human serum was assessed. High recombinant expression of human complement regulatory molecules hCD59 and hDAF was also attained by retroviral transduction of PAC for further analyses. Complement activation on PAC after exposure to $20 \%$ human serum for 24 hours mainly triggered the release of pro-inflammatory cytokines IL-6 and IL-8. Transgenic expression of HT and hCD59 did not suffice to fully counteract this effect. Nevertheless, the combination of blocking anti-Gal antibodies (or C5a) and high hCD59 levels conferred very high protection. On the contrary, high hDAF expression attained the most dramatic reduction in IL-6/IL-8 secretion by a single strategy, but the additional inhibition of anti-Gal antibodies or C5a did not provide further improvement. Notably, we demonstrate that both hCD59 and hDAF inhibit anaphylatoxin release in this setting. In conclusion, our study identifies genetic-engineering approaches to prevent humoral rejection of xenogeneic chondrocytes for use in cartilage repair.
\end{abstract}

Keywords: Xenotransplantation, cartilage, complement, antibody, complement regulatory proteins, cytokine release, anaphylatoxin.

*Address for correspondence:

Cristina Costa,

IDIBELL, Hospital Duran i Reynals,

Gran Via de L'Hospitalet 199,

08908 L'Hospitalet de Llobregat,

Barcelona, SPAIN

Telephone number: +34-93-2607355

Fax number: +34-93-2607426

Email: ccosta@idibell.cat

\section{Introduction}

Cartilage repair is currently the object of intense research, due to the high medical needs associated with cartilage injury and disease and the difficulties encountered in developing effective therapies. Cartilage is an avascular tissue with limited regenerative capacity. Cellular and tissue- engineering therapies are considered the best options for the repair of many cartilage defects. In accordance with this, autologous and allogeneic chondrocytes are grafted into articular cartilage lesions with fair clinical outcomes (Brittberg et al., 1994; Jiang et al., 2011; Cucchiarini et $a l ., 2014)$. Research is also under way to find compatible implants for facial, laryngeal and tracheal reconstruction, with some advances already being made in the clinical setting (Yanaga et al., 2009; Fabre et al., 2013). However, the limited availability of tissue/cells, together with the complexity and high costs of current procedures justifies exploring the use of other cell sources that overcome these problems. Many studies have proposed the use of mesenchymal stem cells (MSC) for clinical applications, but further studies are needed to ensure the patient safety and functional recovery (Jiang et al., 2011; Roelofs et al., 2013).

Xenotransplantation is another less-explored option that also shows great potential for cartilage repair (Costa $e t$ al., 2003; Revell and Athanasiou, 2009; Sommaggio et al., 2009). Xenogeneic donor cells and tissues could be adapted, by genetic engineering, to the intended clinical applications and be produced, under controlled conditions, in sufficient quantities to cover all medical needs (transplantation, tissue-engineering, quality controls). This approach could offer many advantages, as it can produce large amounts of cells isolated from young animals with minimal tissue culture expansion, be used as off-the-shelf products and potentially allow better cartilage repair than with the expanded human chondrocytes. Porcine chondrocytes, in particular, fulfill the biological requirements for effective tissue repair (Fuentes-Boquete et al., 2004; SchulzeTanzil et al., 2009). To develop such strategy for clinical use, it is first necessary to elucidate the molecular and cellular mechanisms that trigger and effect the rejection of xenogeneic chondrocytes and cartilage. Initial studies determined that pig cartilage xenografts are subjected to a slow rejection process, comprising humoral and cellular responses in which the galactose $\alpha 1,3$-galactose (Gal) antigen is a key trigger (Stone et al., 1997; Stone et al., 1998; Costa et al., 2003). More recent studies from our group have focused on characterizing the molecular 
bases of the human cellular response to pig chondrocytes, which express Swine leukocyte antigen (SLA)-I, the potent costimulatory molecule CD86 and the adhesion molecules VCAM-1 and ICAM-1 (Sommaggio et al., 2009). All of them are functionally relevant for a variety of human immune responses, including $\mathrm{T}$ cells and macrophages. Notably, human NK cells lyse pig chondrocytes by using multiple NK activating receptors, including CD16 that leads to antibody-dependent cell-mediated cytotoxicity in the presence of human xenoreactive antibodies (Sommaggio et al., 2012).

Natural xenoantibodies and complement comprise the first barrier that prevents acceptance of xenografts and foreign bodies (i.e. biomaterials). The humoral response against pig chondrocytes is initiated by the deposition of human xenoreactive natural antibodies, mainly recognizing the carbohydrate antigen Gal (Stone et al., 1998; Costa et al., 2003). Complement activation follows antibody deposition on chondrocytes, with effects that are highly particular of this cell type (Happonen et al., 2012; Sommaggio et al., 2013). Notably, exposure of pig chondrocytes to human serum does not result in much cytolysis, but triggers a pro-inflammatory response with cell-surface up-regulation of adhesion molecules and cytokine/chemokine release (Sommaggio et al., 2013). The terminal complex C5b-9 and the anaphylatoxin C5a mainly mediate these effects. Accordingly, treatment of the cartilage implant with $\alpha$-galactosidase, prior to transplantion into cynomolgus monkeys, greatly reduces the anti-Gal antibody response and the inflammatory cellular infiltrate within the graft (Stone et al., 1998). Likewise, cartilage from transgenic pigs expressing human $\alpha 1,2$ fucosyltransferase (HT) displayed a dramatic reduction in Gal expression and in cellular immune infiltrate after subcutaneous implantation in Gal-deficient mice (Costa et al., 2003). Despite these advances, the involvement of anti-non-Gal antibodies was revealed in these studies. In particular, we demonstrated that the blockade of anti-Gal antibodies with saturating concentrations of GAS914 (Katapodis et al., 2002) diminished, but did not abrogate, the deposition of immunoglobulin, C4, C3 and C5b-9 on porcine articular chondrocytes (PAC) (Sommaggio et al., 2013). Furthermore, systemic complement inhibition with an anti-C5 blocking antibody in the Gal-knockout mouse model confirmed its protective effect in vivo, by further reducing inflammation and tissue damage of the cartilage implants (Sommaggio et al., 2013).

The complement system is involved in the physiological and pathological processes of cartilage (John et al., 2007; Ballanti et al., 2011). Chondrocytes and synovial membranes produce most complement components and the release of matrix fragments activates both the alternative and the classical complement pathways (John et al., 2007; Happonen et al., 2010). Further activation can be produced when trauma or surgical intervention involves bleeding, providing more complement and other potentiating proteins (Amara et al., 2010). Importantly, a role of complement is well established in cartilage disease. Complement participates in the active inflammatory phase of osteoarthritis (OA) and is further amplified by proinflammatory cytokines, which stimulate local synthesis of complement proteins (John et al., 2007; Wang et al., 2011). Complement activation also participates in rheumatoid arthritis, which has led to the development of complement inhibitors for this indication (Wang et al., 1995; John et al., 2007; Macor et al., 2012). Thus, controlling the complement system during chondrocyte xenotransplantation could have beneficial effects beyond prevention of xenograft rejection.

The first genetic engineering approaches developed for xenogeneic applications were based on transgenic expression of human complement regulatory proteins (Lambrigts et al., 1998; Costa and Máñez, 2012). Both human CD59 (hCD59) and human DAF (hDAF, hCD55) have shown efficacy in preventing complement activation and hyperacute rejection of vascularized organs in pigto-primate preclinical models. Notably, they continue to be considered key components of the current strategies in development for solid organ xenotransplantation (Miyagawa et al., 2010; McGregor et al., 2012). Despite the subsequent advances in pig genetic engineering with the generation of Gal knockout pigs (Lai et al., 2002), a combination of strategies based on carbohydrate remodeling and complement inhibition seems preferable to overcome humoral rejection.

After identifying multiple molecules involved in triggering humoral and cellular rejection of pig chondrocytes, this team focuses on assessing the potential efficacy of different genetic engineering approaches for preventing the effects of antibody and complement in chondrocyte xenotransplantation. It is the first step in the development of a xenogeneic cellular product for cartilage repair.

\section{Materials and Methods}

\section{PAC isolation, culture and engineering}

PAC were isolated from control, hCD59 (thereafter called CD59) and $\mathrm{HT}^{\mathrm{AT} 20}$ (thereafter called HT) single and double transgenic pigs (Costa et al., 1999; Costa et al., 2002b) as described (Costa et al., 2003). Briefly, articular cartilage was dissected from the joints under sterile conditions and washed twice in sterile PBS with antibiotics at $4{ }^{\circ} \mathrm{C}$. Cartilage pieces were treated with pronase (Sigma) at $0.8 \% \mathrm{w} / \mathrm{v}$ for $1 \mathrm{~h}$ at $37^{\circ} \mathrm{C}$ with stirring and subsequently with $0.4 \%$ collagenase overnight. Cells were collected by centrifugation, sieved, washed and resuspended in Ham's F12 (Life Technologies)/20 \% FBS (Hyclone, Logan, UT, USA) with $0.2 \mathrm{mg} / \mathrm{mL}$ penicillin/streptomycin and $50 \mu \mathrm{g} / \mathrm{mL}$ gentamicin to be finally seeded into tissue culture flasks. PAC were maintained in Ham's F12/DMEM $(1: 1) / 10 \%$ FBS and antibiotics, and in later studies, in DMEM $/ 10 \%$ FBS with $25 \mu \mathrm{g} / \mathrm{mL}$ Endothelial Cell Growth Supplement (Millipore) for expansion.

PAC expressing hCD59 or hDAF were generated by retroviral transduction. First, we obtained pCR2.1/ hCD152-hCD59 (Alexion Pharmaceuticals, Cheshire, CT, USA), cloned hDAF cDNA by RT-PCR, and subcloned them into the EcoR I and Xho I sites of the retroviral vector pLXSN using Takara reagents. A correct clone of each was further amplified and used to transfect PG13 
packing cells (ECACC) using Lipofectamine ${ }^{\mathrm{TM}}-2000$ (Life Technologies), as described by the manufacturer. Viral supernatants were collected after $48 \mathrm{~h}, 0.45 \mu \mathrm{m}$-filtered and stored at $-80{ }^{\circ} \mathrm{C}$ until use. PAC were infected for $6-8 \mathrm{~h}$ using the viral supernatants in the presence of $0.8 \mu \mathrm{g} / \mathrm{mL}$ hexadimethrine bromide (Sigma). At $48 \mathrm{~h}$ post-infection, the cells were cultured in selection media with $500 \mu \mathrm{g} / \mathrm{mL}$ G418 (Invivogen) and maintained in selection for 2 weeks.

\section{Expression analyses and cell sorting}

Characterization of control, CD59, HT- and HTxCD59transgenic PAC was conducted by FACS. Direct fluorescence of cell-surface carbohydrates was performed with fluorescein isothiocyanate (FITC)-conjugated UEAI and GS-IB4 lectins (EY Laboratories, Inc. San Mateo, CA) to detect $\mathrm{H}$ epitope and $\mathrm{Gal}$ antigen, respectively. Indirect immunofluorescence of hCD59 and SLA-I was performed with the respective specific mouse monoclonal antibodies (mAb) BRA10G (Biodesign international, Kennebunk, ME) and PT85A (VMRD, Inc., Pullman, WA). Goat anti-mouse IgG FITC-conjugated antiserum was used as secondary antibody (Life technologies). All incubations were conducted for $30 \mathrm{~min}$ at $4{ }^{\circ} \mathrm{C}$ in V-bottom plates (Nalge Nunc International). Mean fluorescence intensity (MFI) was determined by FACS in a BD Biosciences FACSort.

To assess transgene expression upon cell activation, PAC were left untreated or incubated with $10 \mathrm{ng} / \mathrm{mL}$ human $\mathrm{TNF} \alpha$ (hTNF $\alpha, \mathrm{R} \& \mathrm{D}$ Systems or Miltenyi Biotec) for $24 \mathrm{~h}$. Expression of hCD59, H epitope, Gal antigen and SLA-I was then measured as described above.

For transduced PAC, the G418-selected cells were first cultured as pools and analyzed in a FACScalibur to assess cell-surface expression of the recombinant molecules. Immunofluorescence of hCD59 and hDAF was performed with mouse mAb BRA10G and BRIC216 (Abcam, Cambridge, MA, USA), respectively. Goat anti-mouse IgG FITC-conjugated antiserum was used as secondary antibody. As expression of pooled cells was heterogeneous, we subsequently obtained a large cell population with high expression levels by cell sorting in a MoFlo-XDP highspeed sorter (Beckman Coulter). The resulting cells were cultured and analyzed by FACS in identical manner.

To assess cell activation in various experiments, confluent PAC were either incubated at $37{ }^{\circ} \mathrm{C}$ with $20 \%$ NHS in HBSS for $24 \mathrm{~h}$, with recombinant human C3a (rhC3a) or C5a (rhC5a) (100 and $1000 \mathrm{ng} / \mathrm{mL}, \mathrm{R} \& \mathrm{D}$ Systems) for $14 \mathrm{~h}$, or remained untreated. After harvest, we monitored by FACS cell surface pig ICAM-1 (pICAM-1), VCAM-1 (pVCAM-1) and SLA-I expression with the specific mouse monoclonal antibodies 3A3.81, 5D11 (both from Alexion Pharmaceuticals) and PT85A, respectively. Goat anti-mouse IgG Alexa Fluor 488-conjugated antisera were used as secondary antibody (Life technologies). MFI was determined in a Gallios flow cytometer with Kaluza software (Beckman Coulter).

\section{Antibody and complement deposition}

In the first set of experiments, PAC were cultured to reach confluence, collected by trypsinization, washed and then incubated with $20 \%$ and $40 \%$ C8-depleted human serum (Quidel, San Diego, CA) or the corresponding heatinactivated serum (hiHS) in HBSS for $30 \mathrm{~min}$ at $37^{\circ} \mathrm{C}$. For complement deposition determination, cells were stained with anti-human C3 and anti-human C4 FITC-conjugated antibodies (MP Biomedicals). These initial flow cytometric studies were conducted on a BD Biosciences FACSort.

In a second experimental set, PAC were exposed to $20 \%$ normal human serum (NHS) for $30 \mathrm{~min}$ at $37^{\circ} \mathrm{C}$ and then harvested for staining with an anti-human $\mathrm{C} 5 \mathrm{~b}$ $9 \mathrm{mAb}$ (Quidel Corp., San Diego, CA, USA) followed by FITC-conjugated goat anti-mouse IgG. Samples were analyzed and MFI was determined in a BD Biosciences FACScalibur.

\section{Cytokine determinations after exposure to human serum}

Control and genetically-modified PAC were seeded to confluence in 12-well plates and subsequently incubated at $37^{\circ} \mathrm{C}$ with $20 \%$ and/or $40 \%$ NHS in HBSS, depending on the assays. Serum was isolated from blood samples obtained from the blood bank with authorization of the Clinical Research Ethics Committee of Bellvitge. Untreated PAC, PAC treated with $10 \mathrm{ng} / \mathrm{mL}$ hTNF $\alpha$ and PAC exposed to hiHS were included as controls. After $24 \mathrm{~h}$ incubations, cell culture supernatants were collected, centrifuged at $1500 \times \mathrm{g}$ for $5 \mathrm{~min}$ and used for pig IL-6 (pIL-6) and IL-8 (pIL-8) determinations by ELISA. To this end, we used Quantikine immunoassays (R\&D Systems) following the manufacturer instructions. These ELISA do not produce significant cross-reactivity with human counterparts. Similar procedures were conducted to study the effect of anti-human C5 mAb 557 and 561 (Hycult Biotech, Uden, Netherlands) at $10 \mu \mathrm{g} / \mathrm{mL}$ and GAS914 (Novartis, Basel, Switzerland) at $100 \mu \mathrm{g} / \mathrm{mL}$.

\section{Quantification of C3a, C5a and Bb complement fragments}

The indicated genetically-modified PAC were cultured to reach confluence, collected by short trypsinization, and washed. For C3a and C5a quantifications, 50,000 cells were transferred into $1.5 \mathrm{~mL}$ polypropylene microtubes in duplicates for each condition and incubated in suspension with $20 \%$ NHS, $40 \%$ NHS or the corresponding hiHS controls in HBSS for $30 \mathrm{~min}$ at $37^{\circ} \mathrm{C}$. Serum controls without cells were included. $\mathrm{C} 3 \mathrm{a}$ and $\mathrm{C} 5 \mathrm{a}$ were quantified in supernatants with MicroVue ${ }^{\mathrm{TM}}$ EIA kits (Quidel), following the manufacturer's instructions. For measuring $\mathrm{Bb}$ generation, 100,000 cells were transferred into wells of 96-well glass-bottom plates (P96-1.5-N, In vitro scientific, Sunnyvale, CA, USA), in duplicates for each condition, and incubated in suspension with $40 \%$ NHS, or the corresponding hiHS controls in HBSS, for $30 \mathrm{~min}$ at $37^{\circ} \mathrm{C}$. Serum without cells was also incubated as control. $\mathrm{Bb}$ was determined in supernatants using MicroVue ${ }^{\mathrm{TM}} \mathrm{Bb}$ Plus EIA (Quidel).

\section{Statistical analyses}

The indicated values are expressed as mean \pm standard error of the mean (SEM). Statistical analysis was conducted 
a
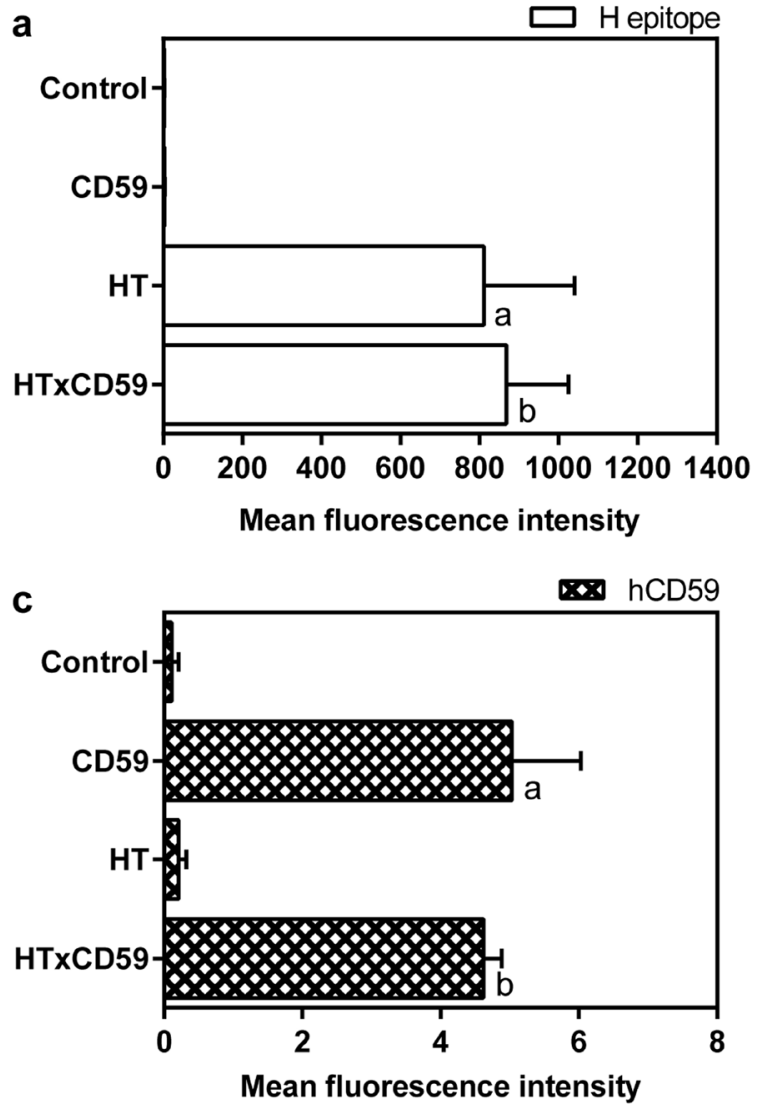
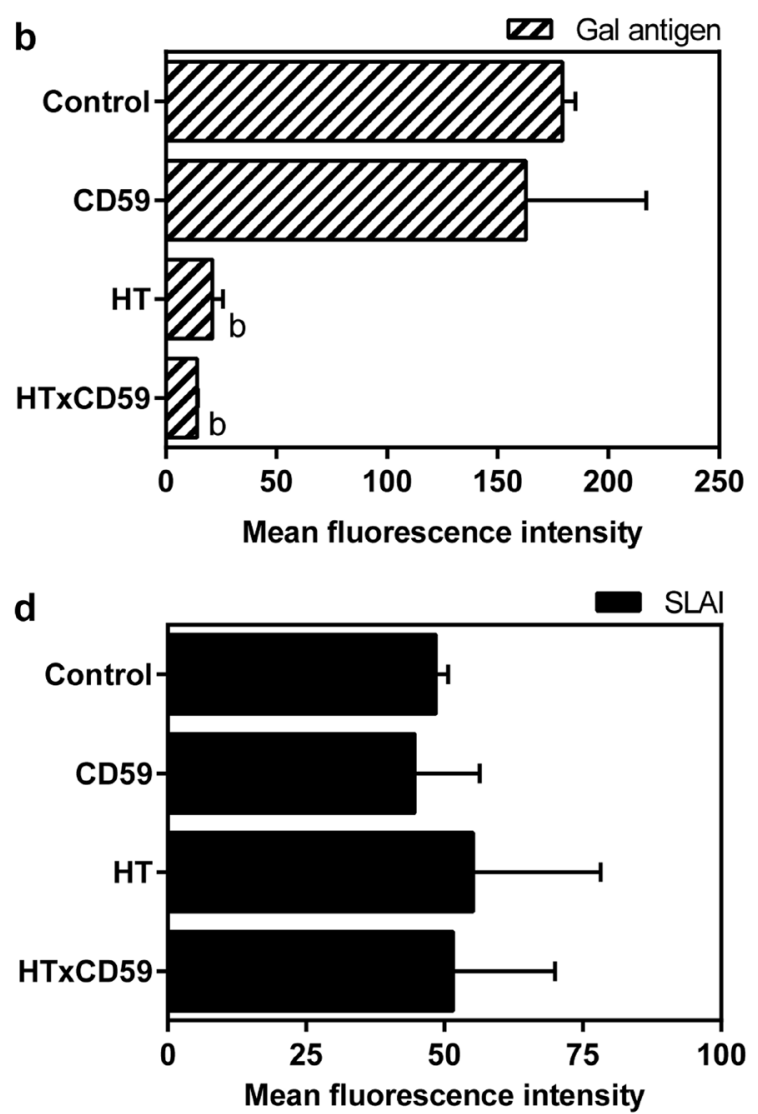

Fig. 1. Characterization of transgenic chondrocytes. Flow cytometric analysis of PAC isolated from control, CD59-, HT- and HTxCD59-transgenic pigs. Staining with UEA-I and GS-IB4 lectins was carried out to detect cell-surface expression of $\mathrm{H}$ epitope (a) and Gal antigen (b), respectively. The expression of hCD59 (c) and SLA-I (d) was also measured with specific $\mathrm{mAb}$. The bars represent the mean \pm SEM of MFI of three independent experiments. Significant differences were observed between transgenic and controls as indicated $\left({ }^{a} p \leq 0.05,{ }^{b} p<0.01\right)$. Transgene expression levels were maintained in the double transgenic PAC.

using 2-tailed Student $t$-test when comparing two groups and ANOVA (applying Tukey) for multiple comparisons. Differences were considered statistically significant at $p \leq 0.05$.

\section{Results}

Characterization of transgenic chondrocytes We characterized PAC obtained from single and double transgenic pigs expressing human HT and CD59 (Costa et al., 1999; Costa et al., 2002b). First, the expression levels of H epitope and hCD59 were determined by flow cytometry (Fig. 1). PAC from HT and HTxCD59-transgenic pigs expressed high levels of $\mathrm{H}$ epitope (assessed with UEA-I lectin), whereas control and CD59-transgenic pig cells showed low background staining (Fig. 1a). The high $\mathrm{H}$-substance expression was accompanied by a dramatic reduction in Gal antigen on the cell surface relative to controls (about $90 \%$ decrease in MFI revealed with GSIB4 lectin) (Fig. 1b). As expected, only CD59- and double transgenic PAC showed hCD59 expression, although at moderate levels (Fig. 1c). All cells showed comparable SLA-I expression as determined for control (Fig. 1d).

Mimicking a pro-inflammatory setting, the next experiments assessed the effect of $24 \mathrm{~h}$ exposure to hTNF $\alpha$ on PAC transgene and Gal antigen expression. The data are summarized in Table 1 and were calculated as ratios of the hTNF $\alpha$-treated PAC relative to resting conditions for each independent experiment and then averaged. First, the regulated expression of the HT and CD59 transgenes was confirmed by observing respectively 1.5 -and 4-fold increases in $\mathrm{H}$ epitope and hCD59 on the cell surface, whereas SLA-I was similarly elevated in all PAC (Table 1). Interestingly, treatment with hTNF $\alpha$ also increased Galantigen staining in control and CD59 PAC, whereas HT and HTxCD59 transgenic PAC showed values closer to 1, indicating that the reduction in Gal antigen was preserved under these conditions (Table 1).

The anti-Gal and total human xenoantibody reactivity is considerably lower on PAC from both HT- (Costa et al., 2003) and double-transgenic pigs, compared to nontransgenic PAC (data not shown). In order to assess the potential for complement activation, we next determined - by flow cytometry - the deposition of human complement components $\mathrm{C} 4$ and $\mathrm{C} 3$ on control, single and double transgenic PAC, incubated with $20 \%$ and $40 \%$ C 8 depleted human serum at $37{ }^{\circ} \mathrm{C}$ (Fig. 2). Our data show a 2- and 6-fold reduction in anti-C4 reactivity in HT- and HTxCD59-transgenic PAC, relative to controls (taking into account MFI values) at both serum concentrations (Fig. $2 \mathrm{a})$. Due to the amplification of the complement cascade, $\mathrm{C} 3$ deposition was markedly increased relative to $\mathrm{C} 4$ in 
Table 1. Effect of TNF $\alpha$ on transgene and Gal antigen expression in PAC from control, CD59-, HT- and HTxCD59-transgenic pigs.

\begin{tabular}{|c|c|c|c|c|}
\hline & Control PAC & CD59 PAC & HT PAC & HTxCD59 PAC \\
\hline H epitope & $1 \pm 0$ & $1 \pm 0$ & $1.55 \pm 0.28$ & $1.44 \pm 0.1$ \\
\hline hCD59 & $1 \pm 0$ & $3.8 \pm 1.1$ & $1 \pm 0$ & $4.16 \pm 1.7$ \\
\hline SLA I & $4.86 \pm 0.67$ & $5.9 \pm 1.4$ & $6.6 \pm 1.6$ & $5 \pm 1.2$ \\
\hline Gal antigen & $1.46 \pm 0.16$ & $1.45 \pm 0.14$ & $1.25 \pm 0.11$ & $1.27 \pm 0.13$ \\
\hline
\end{tabular}

PAC isolated from control and CD59-, HT- and HTxCD59-transgenic pigs were cultured with media alone or with hTNF $\alpha$ for $24 \mathrm{~h}$ and analyzed by flow cytometry for expression of H epitope, hCD59, SLA I and Gal antigen. All data are presented as the mean \pm SEM of ratio between MFI of TNF-treated and untreated $(n=4)$. ANOVA was applied for comparison of the ratios of SLA I and Gal antigen and none reached statistical significance.

a
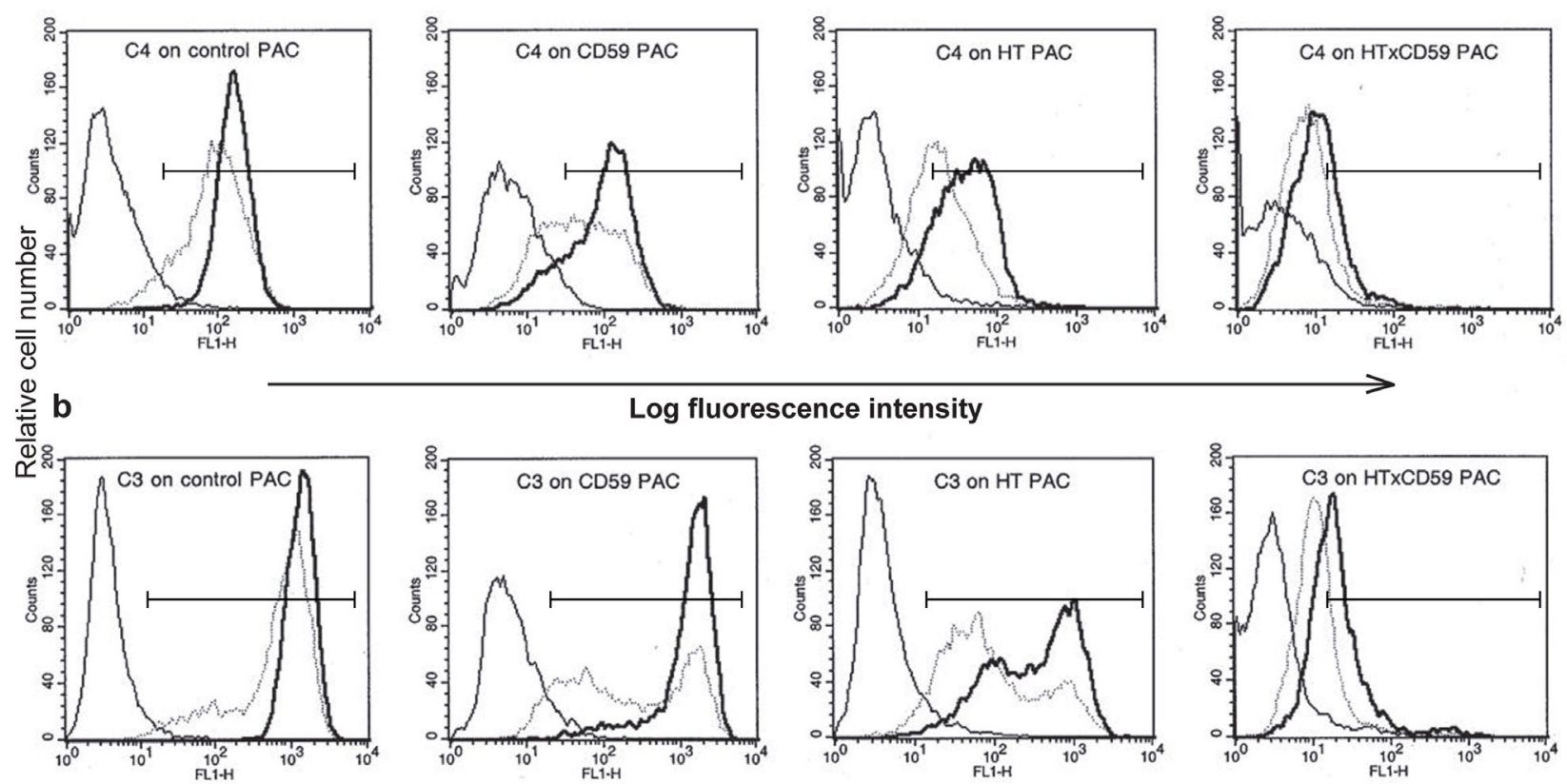

Fig. 2. Determination of complement deposition on transgenic PAC. Flow cytometric analyses of C4 (a) and C3 (b) deposition on PAC isolated from control, CD59-, HT- and HTxCD59-transgenic pigs. Complement reactivity was determined at 40 (thick line) and 20 (dotted line) \% C8-depleted human serum. The thin line corresponds to background reactivity without serum. A marker is placed above the $99 \%$ negative-control population to indicate positivity. Results are representative of three independent experiments.

control and CD59-transgenic cells (Fig. 2b). Notably, HT-transgenic PAC displayed considerably lower C3 reactivity relative to control cells (65\% less MFI at $20 \%$ serum). Moreover, the lowest $\mathrm{C} 3$ deposition was observed on HTxCD59-transgenic PAC $(90 \%$ reduction relative to controls at $20 \%$ serum) (Fig. 2b). In a second set of 4 experiments, we assessed C5b-9 deposition at $20 \%$ human serum and confirmed a diminution in double transgenic PAC, relative to controls $(5.6 \pm 1.7$ vs. $16.5 \pm 2.8 \mathrm{MFI}$, $p=0.015)$.

\section{Transgenic expression of HT and hCD59 in PAC fails to fully protect from the effects of human complement}

We next measured the release of pIL- 6 and pIL-8 from control and transgenic PAC (resting conditions), exposed to $20 \%$ NHS or hiHS control for $24 \mathrm{~h}$ to assess the protective effect of the transgenes (Fig. 3). High cytokine release was observed after NHS exposure. Although no statistical differences were attained between the different PAC, for either pIL-6 or pIL- 8 after calculating the mean of three experiments (there was variability between assays), we did observe a trend of less secretion in HT and double transgenic PAC for both interleukins (Fig. 3). As a control of the cell isolates, we included a hTNF $\alpha$ treatment for $24 \mathrm{~h}$ that led to a comparable response in all of them (2507.7 \pm 332 and $6368.4 \pm 280.4 \mathrm{pg} / \mathrm{mL}$ as the mean $\pm \mathrm{SEM}$ of the respective means of pIL- 6 and pIL- 8 released by the 4 different PAC together).

\section{High expression of hCD59 and hDAF on PAC reduces the response to human complement}

To assess whether high expression of specific human complement regulatory proteins on PAC could modify 
a

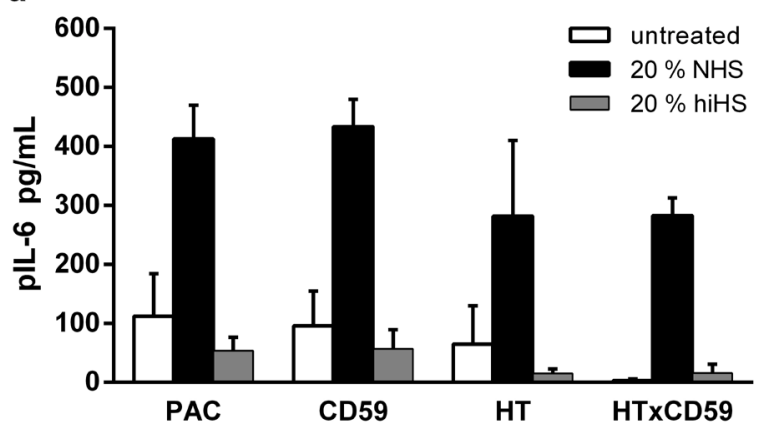

b

Fig. 3. Determination of pIL- 6 and pIL- 8 released by transgenic PAC. The release of pIL-6 (a) and pIL-8 (b) by PAC, control or expressing the indicated transgenes, was determined by ELISA after incubation with $20 \%$ normal human serum (NHS) or the heat-inactivated control (hiHS) for $24 \mathrm{~h}$. The mean \pm SEM of 3 independent experiments is shown. Significant differences were attained between untreated and NHS-treated PAC (not displayed), but not between controls and the various transgenic PAC incubated with NHS.

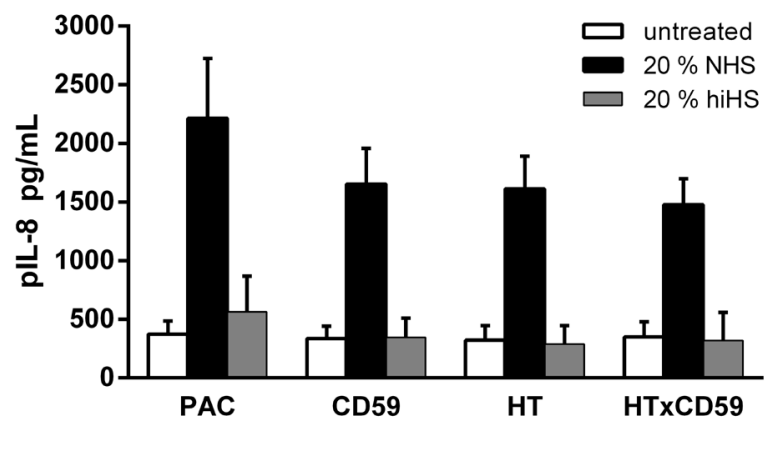

interleukin release and potentially confer protection, we compared the effects of hCD59 and hDAF. To this end, we obtained genetically-engineered PAC expressing either hCD152-hCD59 or hDAF by retroviral transduction and cell sorting, as well as mock-transduced PAC containing the empty pLXSN vector (Fig. 4a). Transduced PAC were incubated next with $40 \%$ NHS or hiHS for $24 \mathrm{~h}$ and pIL-6 and pIL-8 secretion was determined (Fig. 4b,c). Cells expressing hDAF exhibited the highest reduction in pIL-6/pIL-8 release after NHS exposure relative to mock controls (about one third), whereas interleukin secretion in cells expressing hCD59 was still substantially lower than controls.

To further assess the mechanisms of protection for each strategy singly and in combination, we conducted the cytokine-release assay on the genetically modified PAC exposed to NHS alone or in the presence of GAS914 or anti-human C5a mAb 561 (Table 2). The use of saturating concentrations of GAS914 in these experiments markedly reduced cytokine release from control and hCD59expressing PAC, moderately reduced release from HTtransgenic PAC, and did not decrease secretion by PAC expressing hDAF. Likewise, the anti-human C5 mAb 557, which displays a partial inhibitory activity of membrane attack complex (MAC) formation (Sommaggio et al., 2013), also reduced a substantial proportion $(\sim 40 \%)$ of cytokine release by HT PAC, although not as much as for control PAC (data not shown). Interestingly, the use of a blocking $\mathrm{mAb}$ specific for human $\mathrm{C} 5 \mathrm{a}$ did not have as much impact on control PAC and the protective effect was minor or null for the HT transgenic PAC (Table 2). Nevertheless, it led to a consistent reduction in pIL-6/pIL-8 release when combined with high hCD59 expression. Finally, C5a blockade did not diminish interleukin secretion by PAC expressing high levels of hDAF. Thus, expression of $\mathrm{hDAF}$ alone was sufficient to attain high protection and the addition of GAS914 or anti-human C5a mAb to these cells did not provide a better outcome.

\section{Effect of high hCD59 and hDAF expression on complement alternative pathway}

An assay was next developed to determine activation of the alternative pathway on PAC exposed to human serum at $40 \%$ by quantifying the release of $\mathrm{Bb}$ fragments to supernatants (Fig. 5). This release parallels the formation of the alternative pathway $\mathrm{C} 3$ convertase on the cell surface. Controls were included to show low background produced by heat-inactivated serum and some activation generated by serum when exposed to the plate surface in the absence of cells. In this setting, we confirmed activation of the alternative pathway by PAC incubated with NHS. Control PAC showed the highest release of Bb (Fig. 5), which was partially reduced by adding saturating concentrations of GAS914 (4.5 \pm 0.3 vs. $5.6 \pm 0.3, n=3)$. PAC expressing high levels of hDAF produced significantly lower levels of $\mathrm{Bb}$, whereas high hCD59 expression on PAC led to an intermediate release of $\mathrm{Bb}$ that did not reach significance (Fig. 5). Finally, double transgenic HTxCD59 PAC (included for comparison) released a similar amount of $\mathrm{Bb}$ as hDAF-expressing PAC.

\section{High expression of hCD59 and hDAF on PAC reduces anaphylatoxin generation}

We further studied the mechanism of protection of hDAFexpressing PAC, by exposing them directly to a high dose of rhC5a in parallel with controls and determining expression of cell surface activation markers. The data showed a response comparable to that of control PAC (data not shown). At this point, we also considered determining whether rhC3a could induce a similar response in PAC, in order to establish the points of intervention needed to control the full effects of complement activation. However, 
a

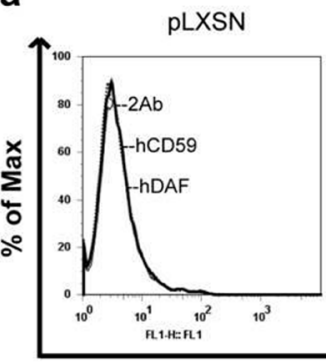

pLXSN-hCD152-hCD59 pLXSN-hDAF

b
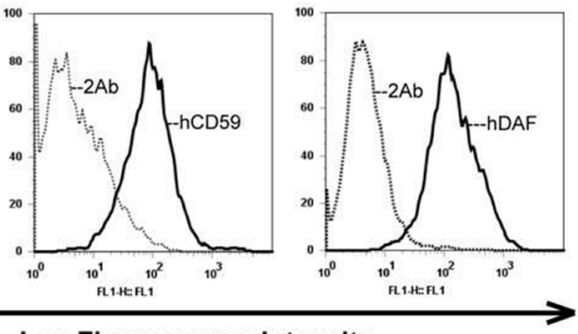

Log Fluorescence Intensity

Fig. 4. Analyses of PAC expressing human complement regulatory proteins. PAC were transduced with retroviruses generated with empty pLXSN, pLXSN-hCD152-hCD59 or pLXSN-hDAF, selected and sorted for highexpressing cells. (a) Representative profile of cell surface expression of hCD59 and hDAF as determined by FACS. Secondary antibody reactivity is presented with dotted line as control. Determination of pIL-6 (b) and pIL-8 (c) secretion by PAC mocktransduced and expressing high levels of hCD59 or hDAF after incubation with $40 \%$ NHS or hiHS for $24 \mathrm{~h}$. The mean \pm SEM of 4 independent experiments is shown. All three cell-lines secreted similar amounts of cytokines in response to hTNF $\alpha$. Significant differences between PAC expressing hCD59 or hDAF versus mock controls were observed after NHS treatment as indicated $\left({ }^{\mathrm{a}} p \leq 0.05\right)$. Significant differences were also attained for pIL-8 between hCD59- and hDAFexpressing PAC exposed to NHS ( $p=0.007$ by paired $t$-test).

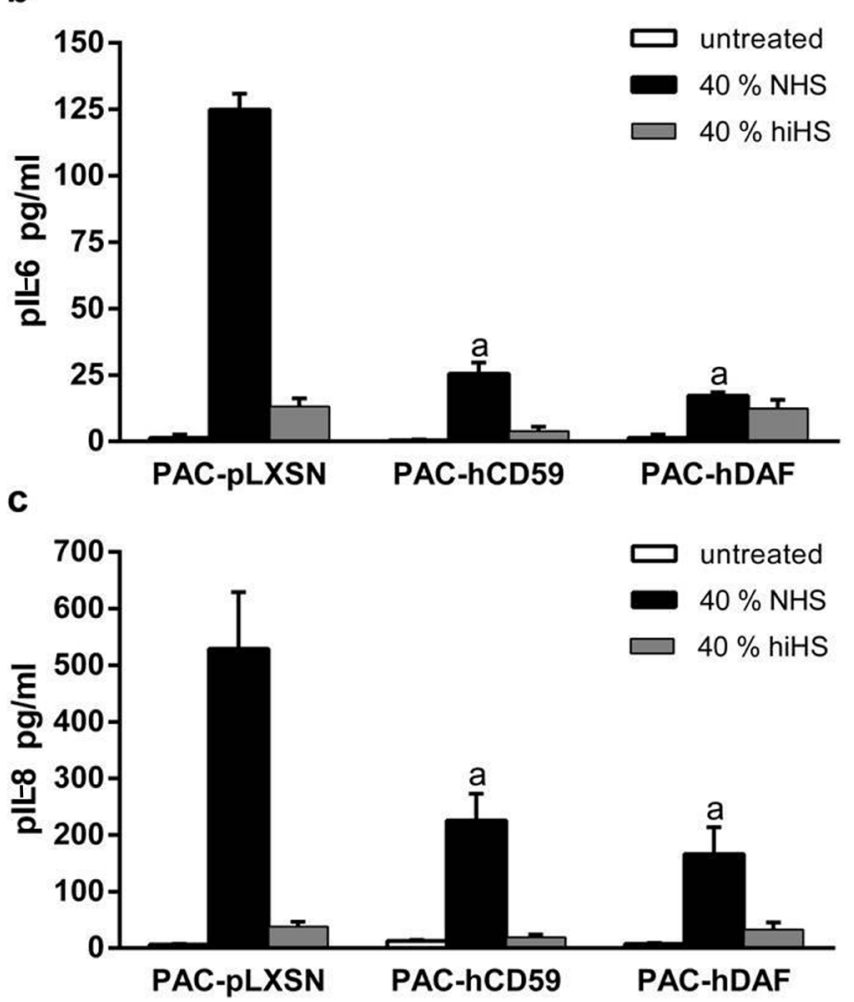

Table 2. Interleukin concentrations in supernatants of PAC cultured with NHS.

\begin{tabular}{|l|c|c|c|c|c|c|c|c|}
\hline & \multicolumn{4}{|c|}{ pIL-6 (pg/mL) } & \multicolumn{4}{c|}{ pIL-8 (pg/mL) } \\
\hline & mock & HT & hCD59 & hDAF & mock & HT & hCD59 & hDAF \\
\hline medium & 3.9 & 0 & 0.8 & 3.9 & 4.7 & 8.2 & 12.9 & 9.4 \\
\hline NHS & 122.7 & 45.8 & 29.8 & 14.9 & 827.8 & 609.1 & 168.2 & 85.8 \\
\hline NHS+GAS & 18.8 & 33.7 & 10.2 & 18.4 & 278.7 & 406.8 & 80 & 109.3 \\
\hline NHS+mAb & 194.4 & 40.4 & 46.2 & 20.8 & 1351 & 592.6 & 315.1 & 108.2 \\
\hline NHS+561 & 50.9 & 29.8 & 16.1 & 22.7 & 760.8 & 646.7 & 134 & 149.3 \\
\hline hiHS & 7.8 & 12.1 & 4.3 & 9 & 14.1 & 20.8 & 5.9 & 7.1 \\
\hline GAS & 0.7 & nd & nd & nd & 6.2 & nd & nd & nd \\
\hline CN mAb & 0.3 & nd & nd & nd & 3.7 & nd & nd & nd \\
\hline
\end{tabular}

Interleukin release of HT-transgenic and transduced PAC cultured for $24 \mathrm{~h}$ with $40 \%$ NHS alone (NHS), or with $100 \mu \mathrm{g} / \mathrm{mL}$ GAS914 (NHS+GAS), $10 \mu \mathrm{g} /$ $\mathrm{mL}$ control $\mathrm{mAb}(\mathrm{NHS}+\mathrm{mAb})$, anti-C5 mAb 561 (NHS+561). Controls with hiHS, GAS914 or control mAb in regular medium are included. Representative experiment of 3 (same for both IL), nd/not determined.

no up-regulation of SLA-I, pICAM-1 or pVCAM-1 was observed, even after incubation with $1000 \mathrm{ng} / \mathrm{mL} \mathrm{rhC3a}$ (data not shown). Then, we measured the release of $\mathrm{C} 3 \mathrm{a}$ and $\mathrm{C} 5 \mathrm{a}$ after incubating the genetically modified PAC with $20 \%$ and $40 \%$ NHS (Fig. 6). This quantification revealed that the heating procedure used to inactivate the complement activity for hiHS controls generated some C5a (Fig. 6c,d). For this reason, additional negative controls of NHS and hiHS, incubated at $37^{\circ} \mathrm{C}$ without cells, were included in the assays. In these experiments, the hDAFexpressing PAC generated significantly less C3a and C5a than mock control cells (Fig. 6a-d). Interestingly, 
Fig. 5. Bb generation by genetically-modified PAC exposed to NHS. Quantification of Bb released to culture supernatants of PAC expressing human complement regulatory proteins (including HTxCD59-transgenic PAC) incubated with $40 \%$ NHS or hiHS for $30 \mathrm{~min}$. Background levels were determined in serum incubated in the absence of cells. The mean \pm SEM of 4 independent experiments is shown. Significant differences were observed between PAC with hDAF or double transgenic HTxCD59 PAC and mock-transduced PAC after NHS exposure as indicated $\left({ }^{\mathrm{a}} p \leq 0.05\right)$.

a

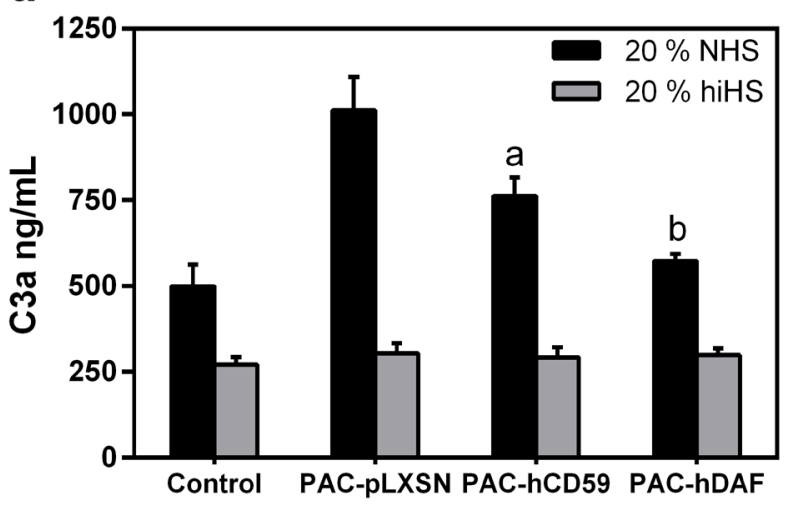

C

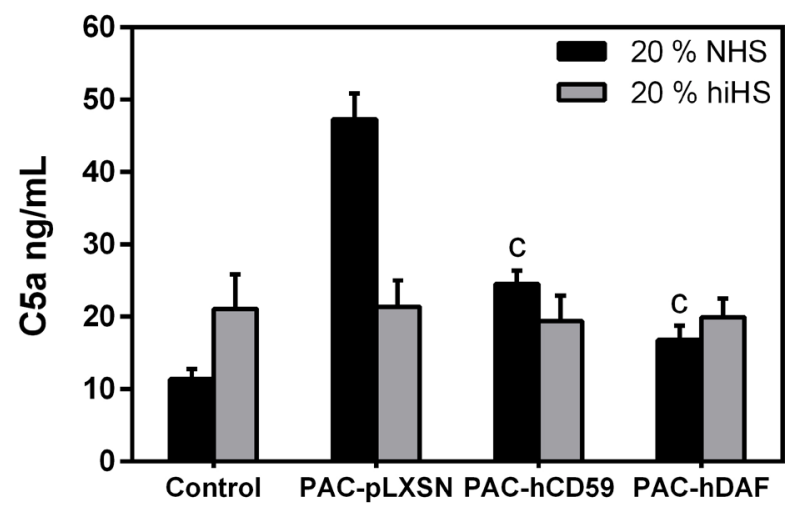

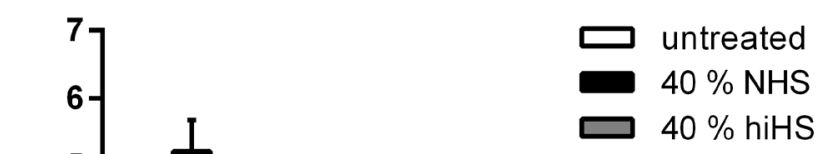

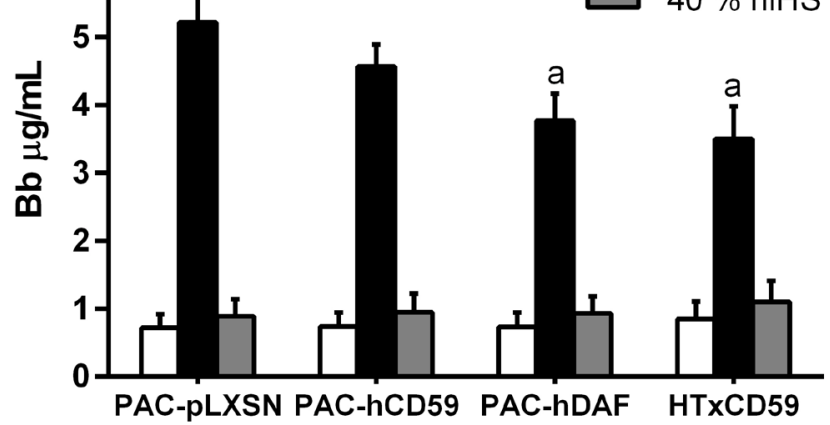

b

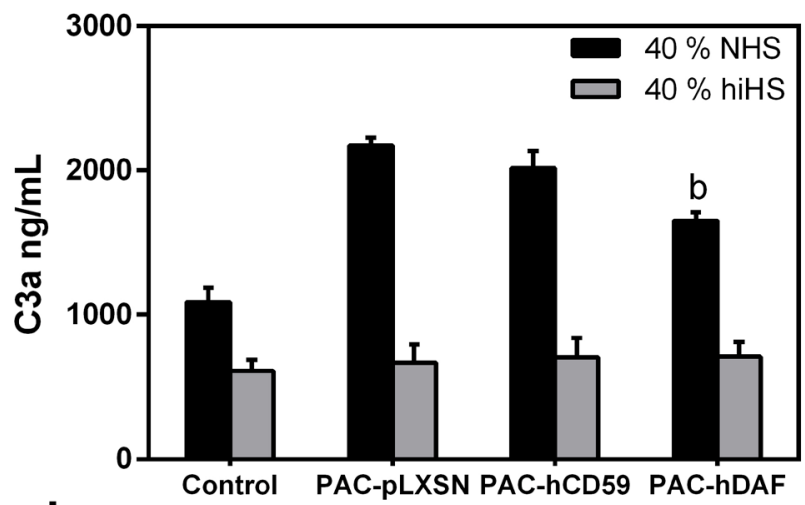

d

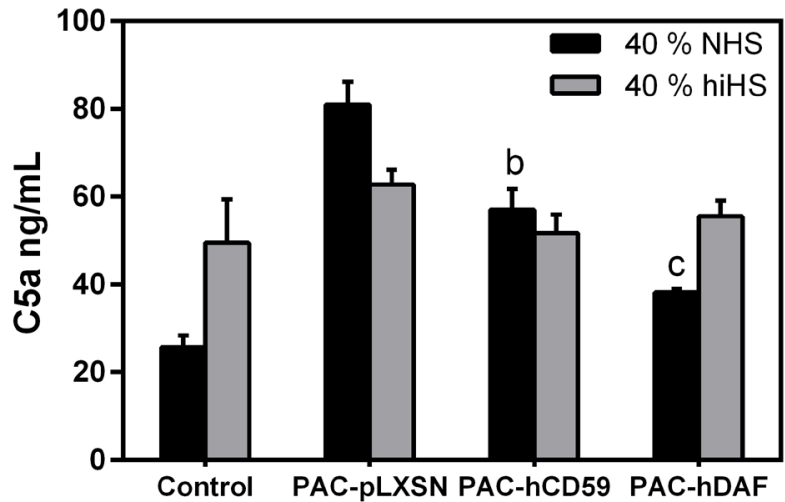

Fig. 6. Anaphylatoxin generation by genetically-modified PAC exposed to NHS. Quantification of C3a (a,b) and C5a (c,d) released to culture supernatants of PAC expressing human complement regulatory proteins incubated with $20 \%$ (a,c) and $40 \%$ (b,d) NHS or hiHS for $30 \mathrm{~min}$. Background levels were determined in serum incubated in the absence of cells (shown as Control). The mean \pm SEM of 4 independent experiments is shown. Significant differences were observed between PAC with hCD59 or hDAF and mock-transduced PAC after NHS exposure as indicated $\left({ }^{\mathrm{a}} p \leq 0.05\right.$, $\left.{ }^{\mathrm{b}} p<0.01,{ }^{\mathrm{c}} p<0.001\right)$. Significance was also attained between mock and hCD59-expressing PAC incubated with NHS relative to NHS without cells, but not for PAC with hDAF versus NHS alone.

PAC expressing high levels of hCD59 also showed lower anaphylatoxin generation than controls when exposed to NHS, especially for C5a, but also for C3a at $20 \%$ NHS.

Very high protection attained by highly expressed hCD59 on HT transgenic PAC

HT transgenic PAC were transduced and selected to express high levels of either hCD59 or hDAF for further comparison of these two molecules. To this end, the various transductants were left untreated or exposed to $20 \%$ NHS for $24 \mathrm{~h}$ and the up-regulation of SLA-I, pICAM-1 and pVCAM-1 was determined on the cell surface by flow cytometry (Fig. 7a,b). Differences in MFI fold increases, relative to resting conditions, were observed for SLA-I and pICAM-1 between mock-control PAC and HT PAC, either mock-transduced or transduced to express the complement inhibitors (Fig. 7a). These two markers were found elevated on control PAC but not on the various HT transductants assessed. The expression of pVCAM-1 was also highly up-regulated on control PAC after NHS exposure (Fig. 7b). 
a

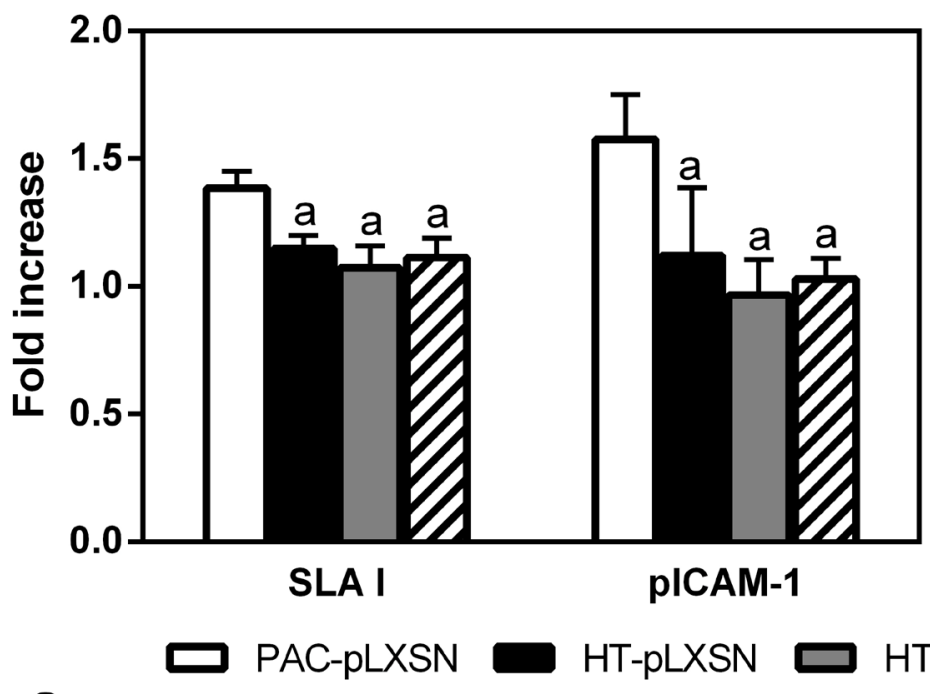

b

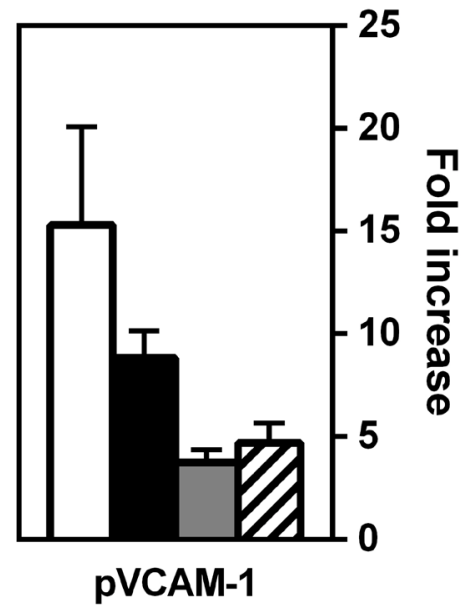

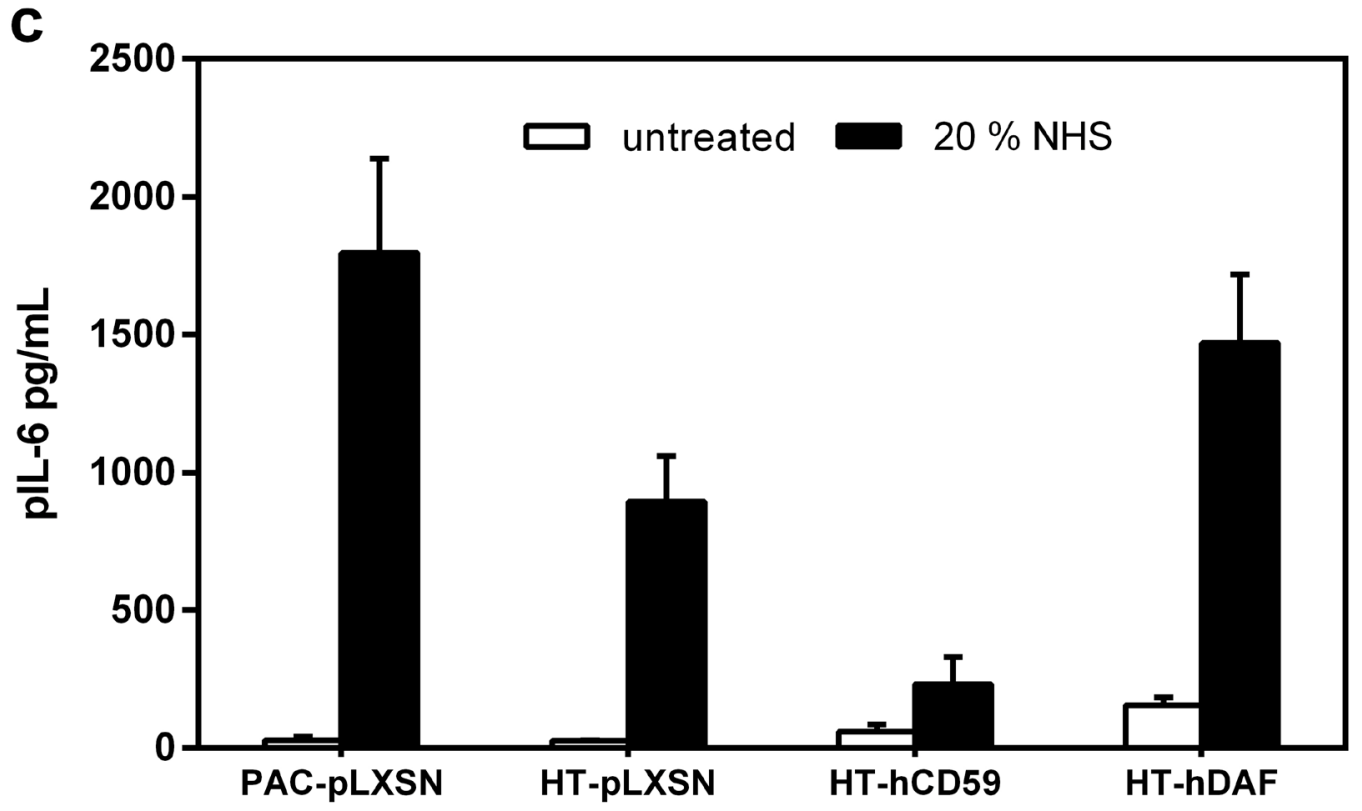

Fig. 7. Analyses of PAC expressing HT and human complement regulatory proteins. HT-transgenic PAC were transduced with retroviruses generated with empty pLXSN, pLXSN-hCD152-hCD59 or pLXSN-hDAF, selected and sorted for high-expressing cells. Mock-transduced control PAC were simultaneously generated. The various PAC (as indicated) were left untreated or exposed to $20 \%$ NHS for $24 \mathrm{~h}$, harvested and analyzed by flow cytometry to assess cell-surface expression of SLA-I, pICAM-1 (a) and pVCAM-1 (b). The bars represent the mean \pm SEM of fold increases in MFI calculated relative to untreated cells and corresponding to 4 independent experiments. Significant differences between transductants of HT PAC and control PAC were observed after NHS treatment as indicated ( ${ }^{\mathrm{a}} p \leq 0.05$ ), but not for other combinations. (c) Secretion of pIL-6 by the same PAC in supernatants harvested after $24 \mathrm{~h}$ incubation. Cytokine release was normalized to one million cells, considering the number of cells recovered for each condition. A representative experiment of 3 independent experiments is shown.

However, the high variability between assays disallowed the detection of any significant reduction in pVCAM-1 expression in the presence of HT. Nevertheless, the data suggested that the complement inhibitors further prevented pVCAM-1 up-regulation relative to HT transgenic PAC (Fig. 7b).

In these experiments, supernatants were also collected to measure pIL-6 release (Fig. 7c). After normalization for cell number due to some cell death observed for control PAC, the HT PAC expressing high levels of hCD59 showed the lowest levels of pIL-6 secretion. On the contrary, the
HT PAC expressing hDAF did not show reduced secretion of pIL- 6 relative to mock-transduced HT PAC.

\section{Discussion}

In this study, we have identified genetic-engineering approaches to prevent humoral rejection of xenogeneic chondrocytes for use in cartilage repair. We have found that transgenic expression of HT in combination with high levels of a complement inhibitor may suffice to prevent 
the effects of human antibody and complement on porcine chondrocytes. Since the pioneering work, conducted with HT-transgenic PAC (Costa et al., 2003), our team has worked on identifying molecules that play a critical role in rejection of pig chondrocytes when used as xenografts. This is the first work that focuses on developing a xenogeneic product for use in cartilage repair based on combining genetic engineering approaches. Despite the complexity of the development process implied by this concept, the simplicity of the resulting genetically-engineered product is very attractive. In its final form, it is conceived to require minimal processing, be used off-the-shelf and transplanted in the absence of immunosuppression. In the xenogeneic setting, hurdles are higher than in allotransplantation. However, tools are available to genetically modify the donor pig and have been extensively utilized for the particular purpose of controlling the humoral response against vascularized xenografts (Lambrigts et al., 1998; Costa and Máñez, 2012). Although strategies that combine a complement inhibitor with carbohydrate remodeling are being tested in preclinical models of solid organ xenotransplantation with limited success (Miyagawa et al., 2010; McGregor et al., 2012), cartilage is avascular and the approach proposed here may well suffice to control the undesired effects caused by the amount of antibody and complement involved in this setting. The cellular assays utilized in this work using $20 \%$ and $40 \%$ NHS mimic conditions of high stringency and should be considered models of preclinical value (Sommaggio et al., 2013). As opposed to measuring cell death, reduction of PAC cytokine release became a suitable parameter for assessing protection from the effects of antibody and complement in this setting. Death of PAC exposed to human serum is very low even after $24 \mathrm{~h}$ incubation (Sommaggio et al., 2013). For this reason, no differences could be detected in survival between PAC from controls, HT and HTxCD59 transgenic pigs when incubated with $20 \%$ NHS in a pilot study (data not shown). Notably, future studies are warranted to assess additional strategies that target the cellular response prior to assessing its efficacy in relevant animal models. Then, studies in non-human primates will be necessary for determining the feasibility of this approach before proceeding to clinical trials.

High expression of a complement inhibitor is needed to prevent the effects of antibody and complement on pig chondrocytes, as demonstrated in the cytokine release assays. This finding is in agreement with our observations that anti-non-Gal antibodies contribute to these undesired events (shown by the partial protection attained with saturating concentrations of GAS914). Thus, the CD59 transgenic pig line available from Alexion and characterized in this work, failed to express sufficient levels of the transgene on chondrocytes to be considered for further development in the current form. Despite the significant reduction in complement activation observed when combined with HT in the double transgenic PAC, the remaining complement activation sufficed to trigger PAC activation as measured by pIL- 6 and pIL- 8 release. Nevertheless, the efficacy of hCD59 and hDAF was demonstrated when high expression of these molecules was attained in the transduced and sorted PAC. Interestingly, our data show that hCD59 is highly up-regulated at the cell surface of the Alexion transgenic PAC after hTNF $\alpha$ treatment. It parallels increases of SLA-I, in keeping with the CD59 transgene being under control of the mouse MHC-class-I promoter H2kb (Fodor et al., 1994; Costa et al., 2002b). As the Gal antigen expression seemed to be augmented on Tumor necrosis factor (TNF)-activated $\mathrm{PAC}$, the regulated expression of the transgene is a trait that may be of use for future developments. In this particular case, it could be achieved by using fetal fibroblasts from the CD59 or double transgenic pigs for further genetic manipulation introducing additional transgenes (under the control of promoters that favor expression in cartilage), and their subsequent use for somatic cell nuclear transfer. Furthermore, other transgenic pig lines that have been generated with hCD59 or in combination with hDAF (Costa and Máñez, 2012) could be studied for this purpose. The possibility of using chimeric hCD152-hCD59 is also very attractive (Costa et al., 2002a) and this is the main reason for using hCD59 here.

The expression of hCD59 led to additional protective effects, not previously described for this molecule. It was first revealed by the reduction in $\mathrm{C} 3$ deposition observed in the CD59-transgenic PAC exposed to NHS relative to corresponding controls and was better appreciated in the double transgenic cells. Although our reagent did not distinguish between $\mathrm{C} 3 \mathrm{~b}$ and $\mathrm{C} 3 \mathrm{~d}$ deposition, which may be of interest for future studies because of their distinct activities, the overall C3 decrease was clear. This occurred despite that hCD59 did not affect human antibody deposition, which was comparable to that of controls $(24.6 \pm 5.7$ and $22.5 \pm 1.2 \mathrm{MFI}$ for IgM, respectively). Importantly, further evidence was provided by the significant reduction in $\mathrm{C} 3 \mathrm{a}$ and $\mathrm{C} 5 \mathrm{a}$ generation found after NHS exposure of hCD59-transduced PAC relative to controls. Thus, this effect cannot be explained by the described mode of action of hCD59 that prevents binding of $\mathrm{C} 8$ and $\mathrm{C} 9$ to C5b-7 and formation of the membrane attack complex (Rollins et al., 1991; Ricklin et al., 2010). Consistent with our findings, Holguin et al. reported that C3 accumulates on red blood cells lacking hDAF when hCD59 is blocked by antibodies (Holguin et al., 1992). Elucidating the molecular bases of this mechanism is beyond the scope of this work, but we can speculate that hCD59 itself displays a not-yet-described function, such as decay accelerating activity (probably to a lesser extent than hDAF). In fact, the observed reductions in $\mathrm{C} 3 \mathrm{a}$ and $\mathrm{C} 5$ a release indicated a more pronounced inhibitory effect on C5-convertase than $\mathrm{C} 3$-convertase activity for both hCD59 and hDAF. Alternatively, hCD59 could facilitate the activity of other complement regulatory proteins in a way such as hMCP displays cofactor activity for factor I.

The activation of the complement alternative pathway after exposure of pig chondrocytes to xenogeneic serum was demonstrated for the first time in this work. Furthermore, it was lower in the GAS914-treated samples and HTxCD59-double transgenic PAC, consistent with the alternative pathway acting as an amplification loop for the classical pathway. Considering that extracellular matrix components generated during cartilage remodeling also trigger the alternative pathway, the addition of a 
complement inhibitor to the whole strategy is further justified. The type of determination chosen to measure the alternative-pathway activation, proportional release of $\mathrm{Bb}$ to the supernatant, did not allow proper quantification of the inhibitory capacity of hDAF in this system. Nevertheless, $\mathrm{hDAF}$ expression led to a significant reduction in $\mathrm{Bb}$ generation in spite of the decay accelerating activity probably enhancing the $\mathrm{Bb}$ release. In contrast, high expression of hCD59 produced no significant effect on $\mathrm{Bb}$ (although the same limitation described for hDAF could apply if it actually had some decay accelerating activity).

Various features of hDAF support its use for this particular application. The protection conferred by hDAF from the cytokine release was to some extent superior to that of hCD59 when assessed as single strategies. A contributor factor to this advantage could be the abovementioned capacity of hDAF to inhibit the alternative pathway. Nevertheless, its protection is likely mediated by hDAF's strong capacity to prevent C5b-9 formation and $\mathrm{C} 5 \mathrm{a}$ generation through its $\mathrm{C} 3 / \mathrm{C} 5$-convertase-decay activity. This would explain the lack of blockade attained by the anti-C5a mAb 561 when used with hDAF-expressing PAC. In addition, a defect in the response of these cells to $\mathrm{C} 5 \mathrm{a}$ was ruled out. Our team has previously reported that $\mathrm{C} 5 \mathrm{a}$ directly triggers pIL-6 and pIL-8 secretion by PAC, although C5b-9 also contributes (Sommaggio et al., 2013). In this work, we additionally discarded a major participation of C3a to PAC activation (as determined by up-regulation of cell-surface markers). Note, however, that a reduction in overall anaphilatoxin generation will always be beneficial in this setting as anaphilatoxins not only act on the transplanted chondrocytes, but also produce pro-inflammatory effects on the surrounding tissue and directly promote the cellular immune response (Sacks and Zhou, 2012). Interestingly, a serendipitous result from these experiments was finding C5a elevated in our freshlyprepared heat-inactivated human serum. This should be taken into account for future studies and could explain some previous results such as pVCAM-1 up-regulation by this type of serum control (Sommaggio et al., 2013). Finally, the combination of hDAF with a carbohydrate modification strategy may still be of interest to prevent the effects of xenoreactive antibodies. However, expression of hDAF on HT PAC did not provide better protection than the combination of HT and high hCD59 expression. This concept is reinforced by the fact that highly-expressed hCD59 in combination with GAS914 was extremely effective in preventing PAC cytokine release.

Our work also demonstrates the feasibility of using the HT transgenic approach in combination with a complement regulatory protein to control the humoral immune response against pig chondrocytes. The HT transgenic pig lines generated by Alexion express high levels of $\mathrm{H}$ epitope in cartilage resulting in dramatic reductions in Gal antigen, as well as no anti-Gal-elicited antibody response and lower titers of total anti-pig antibodies when transplanted subcutaneously in Gal-deficient mice (Costa et al., 2003). Taking into account that various reports including the present work describe the involvement of anti-non Gal antibodies in rejection of xenogeneic chondrocytes (Stone et al., 1998; Costa et al., 2003), the effect of residual Gal antigen may be negligible. That is, the HT transgenic approach may be equivalent to the $\mathrm{Gal} \mathrm{KO}$ when combined with a complement inhibitor for this particular application. Comparative studies of these two approaches are still pending and may be of interest for future work. Note that high HT expression provides beneficial effects beyond the antibody response by directly lowering human monocyte adhesion and susceptibility to human NK-cell mediated lysis (Kwiatkowski et al., 1999; Costa et al., 2002a; Costa et al., 2008). However, there is controversy as to whether this protection is produced by the reduction in Gal antigen, as porcine endothelial cells isolated from $\mathrm{Gal} \mathrm{KO}$ pigs show cellular innate immunity similar to controls (Baumann et al., 2005; Schneider et al., 2009). All these properties of the HT transgenic approach remain to be confirmed, in a relevant preclinical animal model. Nevertheless, all the data gathered so far suggest HT could help the complement inhibitors to control not only rejection of PAC xenografts, but also other inflammatory processes such as OA. In theory, good cellular therapies of cartilage repair may prevent the subsequent development of OA and could be used for the repair of OA cartilage.

\section{Conclusions}

This work demonstrates the efficacy of a combinatorial approach, based on transgenic expression of HT and a complement regulatory molecule such as hCD59, to prevent the effects of antibody and complement on xenogeneic chondrocytes. Additional modifications aimed at controlling the cellular response may lead to the generation of a cellular product that could be used off-theshelf for the repair of cartilage defects.

\section{Acknowledgments}

We gratefully acknowledge M Uribe-Herranz, SR Casinghino and NK Bell for helping in PAC isolation and A Gimeno-Sandig and Alexion's staff for providing pig joints. This work was initiated by Alexion Pharmaceuticals, Inc. with a grant from National Institutes of Standards and Technology - Advanced Technology Program (\#70NANB8H4054). It has been funded by Fundación de Investigación Médica Mútua Madrileña (338/05), Fundació La Marató de TV3 (2007-082430), Ministerio de Educación y Ciencia (SAF2008-00499) and Ministerio de Ciencia e Innovación (PI11/02179), all granted to CC, and co-funded by FEDER funds. CC was supported by the Ramón y Cajal program from Ministerio de Ciencia y Tecnología (Spain) and IDIBELL, and MP-C by an IDIBELL fellowship. RS benefited from a one-year fellowship from Fundació Catalana de Trasplantament. None of the authors has a conflict of interest for the present work. 


\section{References}

Amara U, Flierl MA, Rittirsch D, Klos A, Chen H, Acker B, Brückner UB, Nilsson B, Gebhard F, Lambris JD, Huber-Lang M. (2010) Molecular intercommunication between the complement and coagulation systems. J Immunol 185: 5628-5636.

Ballanti E, Perricone C, di Muzio G, Kroegler B, Chimenti MS, Graceffa D, Perricone R (2011) Role of the complement system in rheumatoid arthritis and psoriatic arthritis: relationship with anti-TNF inhibitors. Autoimmun Rev 10: 617-623.

Baumann BC, Schneider MK, Lilienfeld BG, Antsiferova MA, Rhyner DM, Hawley RJ, Seebach JD (2005) Endothelial cells derived from pigs lacking Gal alpha(1,3)Gal: no reduction of human leukocyte adhesion and natural killer cell cytotoxicity. Transplantation 79: 1067-1072.

Brittberg M, Lindahl A, Nilsson A, Ohlsson C, Isaksson O, Peterson L (1994) Treatment of deep cartilage defects in the knee with autologous chondrocyte transplantation. N Engl J Med 331: 889-895.

Costa C, Zhao L, Burton WV, Bondioli KR, Williams BL, Hoagland TA, Ditullio PA, Ebert KM, Fodor WL (1999) Expression of the human alpha1,2-fucosyltransferase in transgenic pigs modifies the cell surface carbohydrate phenotype and confers resistance to human serummediated cytolysis. FASEB J 13: 1762-1773.

Costa C, Barber DF, Fodor WL (2002a) Human NK cell-mediated cytotoxicity triggered by CD86 and Gal alpha 1,3-Gal is inhibited in genetically modified porcine cells. J Immunol 168: 3808-3816.

Costa C, Zhao L, Burton WV, Rosas C, Bondioli KR, Williams BL, Hoagland TA, Dalmasso AP, Fodor WL (2002b) Transgenic pigs designed to express human CD59 and $\mathrm{H}$-transferase to avoid humoral xenograft rejection. Xenotransplantation 9: 45-57.

Costa C, Brokaw JL, Wang Y, Fodor WL (2003) Delayed rejection of porcine cartilage is averted by transgenic expression of $\alpha 1,2$-fucosyltransferase. FASEB J 17: 109-111.

Costa C, Brokaw JL, Fodor WL (2008) Characterization of cartilage from $\mathrm{H}$-transferase transgenic pigs. Transplant Proc 40: 554-556.

Costa Vallés C, Máñez Mendiluce R (2012) Transgenic organs and xenotransplants. Adv Exp Med Biol 741: 73-88.

Cucchiarini M, Madry H, Guilak F, Saris DB, Stoddart MJ, Koon Wong M, Roughley P (2014) A vision on the future of articular cartilage repair. Eur Cell Mater 27: 1216.

Fabre D, Kolb F, Fadel E, Mercier O, Mussot S, Le Chevalier T, Dartevelle P (2013) Successful tracheal replacement in humans using autologous tissues: an 8-year experience. Ann Thorac Surg 96: 1146-1155.

Fodor WL, Williams BL, Matis LA, Madri JA, Rollins SA, Knight JW, Velander W, Squinto SP (1994) Expression of a functional human complement inhibitor in a transgenic pig as a model for the prevention of xenogeneic hyperacute organ rejection. Proc Natl Acad Sci U S A 91: 11153-11157.

Fuentes-Boquete I, López-Armada MJ, Maneiro E, Fernández-Sueiro JL, Caramés B, Galdo F, de Toro FJ,
Blanco FJ (2004) Pig chondrocyte xenoimplants for human chondral defect repair: an in vitro model. Wound Repair Regen 12: 444-452.

Holguin MH, Martin CB, Bernshaw NJ, Parker CJ (1992) Analysis of the effects of activation of the alternative pathway of complement on erythrocytes with an isolated deficiency of decay accelerating factor. J Immunol 148: 498-502.

Happonen KE, Saxne T, Aspberg A, Mörgelin M, Heinegård D, Blom AM (2010) Regulation of complement by cartilage oligomeric matrix protein allows for a novel molecular diagnostic principle in rheumatoid arthritis. Arthritis Rheum 62: 3574-3583.

Happonen KE, Fürst CM, Saxne T, Heinegård D, Blom AM (2012) PRELP protein inhibits the formation of the complement membrane attack complex. J Biol Chem 287: 8092-8100.

Jiang YZ, Zhang SF, Qi YY, Wang LL, Ouyang HW (2011) Cell transplantation for articular cartilage defects: principles of past, present, and future practice. Cell Transplant 20: 593-607.

John T, Stahel PF, Morgan SJ, Schulze-Tanzil G (2007) Impact of the complement cascade on posttraumatic cartilage inflammation and degradation. Histol Histopathol 22: 781-790.

Katopodis AG, Warner RG, Duthaler RO, Streiff MB, Bruelisauer A, Kretz O, Dorobek B, Persohn E, Andres H, Schweitzer A, Thoma G, Kinzy W, Quesniaux VF, Cozzi E, Davies HF, Mañez R, White D (2002) Removal of anti-Galalpha1,3Gal xenoantibodies with an injectable polymer. J Clin Invest 110:1869-1877.

Kwiatkowski P, Artrip JH, Edwards NM, Lietz K, Tugulea S, Michler RE, McKenzie IF, Sandrin MS, Itescu S (1999) High-level porcine endothelial cell expression of alpha(1,2)-fucosyltransferase reduces human monocyte adhesion and activation. Transplantation 67: 219-226.

Lai L, Kolber-Simonds D, Park KW, Cheong HT, Greenstein JL, Im GS, Samuel M, Bonk A, Rieke A, Day BN, Murphy CN, Carter DB, Hawley RJ, Prather RS (2002) Production of alpha-1,3-galactosyltransferase knockout pigs by nuclear transfer cloning. Science. 295: 1089-1092.

Lambrigts D, Sachs DH, Cooper DK (1998) Discordant organ xenotransplantation in primates: world experience and current status. Transplantation 66: 547-561.

Macor P, Durigutto P, De Maso L, Garrovo C, Biffi S, Cortini A, Fischetti F, Sblattero D, Pitzalis C, Marzari R, Tedesco F (2012) Treatment of experimental arthritis by targeting synovial endothelium with a neutralizing recombinant antibody to C5. Arthritis Rheum 64: 25592567.

McGregor CG, Ricci D, Miyagi N, Stalboerger PG, Du Z, Oehler EA, Tazelaar HD, Byrne GW (2012) Human CD55 expression blocks hyperacute rejection and restricts complement activation in Gal knockout cardiac xenografts. Transplantation 93: 686-692.

Miyagawa S, Yamamoto A, Matsunami K, Wang D, Takama Y, Ueno T, Okabe M, Nagashima H, Fukuzawa M (2010) Complement regulation in the GalT KO era. Xenotransplantation 17: 11-25.

Revell CM, Athanasiou KA (2009) Success rates and immunologic responses of autogenic, allogenic, and 
xenogenic treatments to repair articular cartilage defects. Tissue Eng Part B Rev 15: 1-15.

Ricklin D, Hajishengallis G, Yang K, Lambris JD (2010) Complement: a key system for immune surveillance and homeostasis. Nat Immunol 11: 785-797.

Roelofs AJ1, Rocke JP, De Bari C (2013) Cell-based approaches to joint surface repair: a research perspective. Osteoarthritis Cartilage 21: 892-900.

Rollins SA, Zhao J, Ninomiya H, Sims PJ (1991) Inhibition of homologous complement by CD59 is mediated by a species-selective recognition conferred through binding to $\mathrm{C} 8$ within $\mathrm{C} 5 \mathrm{~b}-8$ or $\mathrm{C} 9$ within $\mathrm{C} 5 \mathrm{~b}-9$. J Immunol 146:2345-2351.

Sacks SH, Zhou W (2012) The role of complement in the early immune response to transplantation. Nat Rev Immunol 12: 431-442.

Schneider MK, Ghielmetti M, Rhyner DM, Antsiferova MA, Seebach JD (2009) Human leukocyte transmigration across Galalpha(1,3)Gal-negative porcine endothelium is regulated by human CD18 and CD99. Transplantation 87: 491-499.

Schulze-Tanzil G, Müller RD, Kohl B, Schneider N, Ertel W, Ipaktchi K, Hünigen H, Gemeinhardt O, Stark R, John T (2009) Differing in vitro biology of equine, ovine, porcine and human articular chondrocytes derived from the knee joint: an immunomorphological study. Histochem Cell Biol 131: 219-229.

Sommaggio R, Máñez R, Costa C (2009) TNF, pig CD86 and VCAM-1 identified as potential targets for intervention in xenotransplantation of pig chondrocytes. Cell Transplant. 18: 1381-1393.

Sommaggio R, Cohnen A, Watzl C, Costa C (2012) Multiple receptors trigger human NK cell-mediated cytotoxicity against porcine chondrocytes. J. Immunol 188: $2075-2083$.

Sommaggio R, Pérez-Cruz M, Brokaw JL, Máñez R, Costa C (2013) Inhibition of complement component C5 protects porcine chondrocytes from xenogeneic rejection. Osteoarthritis Cartilage 21: 1958-1967.

Stone KR, Walgenbach AW, Abrams JT, Nelson J, Gillett N, Galili U (1997) Porcine and bovine cartilage transplants in cynomolgus monkey. I. A model for chronic xenograft rejection. Transplantation 63: 640-645.

Stone KR, Ayala G, Goldstein J, Hurst R, Walgenbach A, Galili U (1998) Porcine cartilage transplants in the cynomolgus monkey. III. Transplantation of alphagalactosidase-treated porcine cartilage. Transplantation 65: 1577-1583.

Wang Y, Rollins SA, Madri JA, Matis LA (1995) Anti-C5 monoclonal antibody therapy prevents collageninduced arthritis and ameliorates established disease. Proc Natl Acad Sci USA 92: 8955-8959.

Wang Q, Rozelle AL, Lepus CM, Scanzello CR, Song JJ, Larsen DM, Crish JF, Bebek G, Ritter SY, Lindstrom
TM, Hwang I, Wong HH, Punzi L, Encarnacion A, Shamloo M, Goodman SB, Wyss-Coray T, Goldring SR, Banda NK, Thurman JM, Gobezie R, Crow MK, Holers VM, Lee DM, Robinson WH (2011) Identification of a central role for complement in osteoarthritis. Nat Med 17: 1674-1679.

Yanaga H, Imai K, Fujimoto T, Yanaga K (2009) Generating ears from cultured autologous auricular chondrocytes by using two-stage implantation in treatment of microtia. Plast Reconstr Surg 124: 817-825.

\section{Discussion with Reviewers}

Reviewer I: Given the fantastic capacity of the immune system to recognize foreign antigens expressed in low abundance, will the transfer of xenograft tissue ever be a viable option for lesion repair without the use of immunosuppression at some level?

Authors: The corresponding author has led this research line for many years because she is convinced that it will be technically feasible that chondrocytes are obtained from pigs for use in clinical therapies for cartilage repair. Despite the challenges implied in cartilage repair, the chondrocytes display some advantages related to immune privilege that could facilitate the path to reach this goal of a xenogeneic therapy that does not require additional immunosuppression. Taking into account the major advances that have been made in genomics and animal engineering, it appears that each immunological hurdle that is identified can be overcome through genetic engineering. As represented by this work, the same mechanisms that nature uses to induce and maintain immune homeostasis and tolerance could be adapted for this purpose.

Reviewer II: What other complement regulatory proteins can be regulated by CD59, which itself is a terminal complement regulatory protein?

Authors: We favor the concept of hCD59 displaying some decay accelerating activity as it is a small molecule with an already reported function of disrupting the binding of C5b7 with C8 and C9. However, we cannot rule out without experimental evidence that other proteins contribute to this function. As similar observations have been made with red blood cells expressing only hCD59, hCD59 may be facilitating the complement inhibitory activity of certain serum proteins in a way such as MCP displays cofactor activity for factor I.

Editor's Note: Scientific Editor in charge of the paper: Chris Evans. 